\title{
Development of a Mixer for Concrete Production
}

\author{
Daniyan Ilesanmi A. ${ }^{1,}$, Aderoba Adeyemi A. ${ }^{1}$, Jimmy Daniel N. ${ }^{1}$, Rominiyi Oluwashina L. ${ }^{1}$, \\ Adewumi Deborah $\mathbf{F}^{2}$
}

${ }^{1}$ Department of Mechanical and Mechatronics Engineering, Afe Babalola University, Ado Ekiti, Nigeria

${ }^{2}$ Department of Chemistry, Afe Babalola University, Ado Ekiti, Nigeria

\section{Email address:}

afolabiilesanmi@yahoo.com (Daniyan I. A.)

${ }^{*}$ Corresponding author

\section{To cite this article:}

Daniyan Ilesanmi A., Aderoba Adeyemi A., Jimmy Daniel N., Rominiyi Oluwashina L., Adewumi Deborah F. Development of a Mixer for Concrete Production. American Journal of Engineering and Technology Management. Vol. 2, No. 3, 2017, pp. 20-24.

doi: 10.11648/j.ajetm.20170203.11

Received: June 3, 2017; Accepted: July 10, 2017; Published: August 9, 2017

\begin{abstract}
In an attempt to improve the production of concrete and make its mixing easy, a $700 \mathrm{~mm} \times 530 \mathrm{~mm}$ drum size of a concrete mixing machine was designed and fabricated. The machine parts were made of mild steel, because of its availability and versatile machinability. The efficiency was examined using cement, sand and coarse aggregate with water was added to the dry mix to form a paste and then thoroughly mixed by the machine. The machine is capable of mixing concrete of $50 \mathrm{~kg}$ and the mixing time was found to be relatively equal to the time of mixing using the conventional concrete mixer. When the mixing was performed manually, results obtained indicated that the developed concrete mixer is highly efficient in operation with shorter processing time and higher processing capacity as opposed to the manual method, hence, the fabricated machine can be used for batch production of concrete for improved and effective mixing operations in construction sites.
\end{abstract}

Keywords: Aggregate, Concrete, Efficiency, Mixer, Paste

\section{Introduction}

A concrete mixer is a machine that homogeneously combines cement, aggregate (sand or gravel and water) to form cement (Hunker, 2000). These constituent materials properly proportioned are mixed together with water to form the concrete. The cement serves as the binder to the aggregates while the aggregates serve as the filler materials that give strength to concrete (Aguwa, 2010). The strength of concrete depends upon the strength of these components, their deformation properties, and the adhesion between the paste and aggregate surface (Berntsson et al., 1990; Rashid and Mansur, 2009). The most important variables in achieving high strength concrete are the water-cement ratio (Peterman and Carrasquillo, 1986; Rashid 2002), and curing time (Aguwa 2006). According to Rashid (2009), high strength concrete produced by conventional mixing technologies are usually prepared with water-cement ratios in the range of 0.22 to 0.40 , and their 28 days compressive strength is about 60 to $130 \mathrm{MPa}$ when normal density aggregates are used (FIP/CEB, 1990). Concrete batching plants have developed from simple self-loading mixers to the current high technology plants. Modern day plants have high processing capacity and yield high quality concrete (Apollo, 2014). Concrete mixing machine mainly comprises of cement concrete mixing equipment, cement concrete transit mixer truck, and concrete mixer pump (Liu, 2015). According to Zhengzhouchangli (2016), concrete mixer had existed such as the compulsory concrete mixer, diesel concrete mixer, electric concrete mixer, mobile concrete mixer, self-loading concrete mixer, self-falling concrete mixer etc. The challenge now is the development of a concrete producing machine with high degree of automation that will balance energy saving capacity with efficient operations so as to meet the increasing demand of modern constructions. According to Aguwa (2010), concrete can be produced by employing either mechanical or manual mixing methods.

At first concrete was first made by hand. In this method, the materials are spread on a platform in the desired proportions, turned over and mixed with shovels or hoes, then wet and mixed again. Then the public began to see the great advantages of concrete construction, it was found 
impossible to mix the concrete by hand on account of the inefficiency and as a result inferior quality produced. Inventors set about to develop a mechanical mixer that would beat the old style method in speed and quality of mixture produced. Although, the first mixers were crude in design, they supplant hand mixing and the products of the various inventors have been put upon the market. The researcher examined the mechanical system of the conventional concrete mixer and fashion out a system different from it which still performs the same operation at optimum cost. This encompasses simplicity in design by studying, and analyzing the various mechanical system of concrete mixer currently in use while analyzing various problems associated with the systems in order to develop a simple systems. The correct design analysis suitable for the mechanical system of the mixer was made that can work under various conditions. Concrete batch plants and processing technologies have continued to grow overtime due to rising demand for concrete by commercial and real estate construction. The current type of machinery and technologies used by these plants has continually improved to cater for high demand and ensure that aggregate, binders, additives and admixtures are thoroughly mixed. Hence the aim of this work is to develop a semi-automated batch wise machine for concrete production that is efficient in operation, cost effective, serviceable with high loading and unloading capacity. This will go a long way in solving challenges of fatigue, improper mixing, low processing capacity as well as long mixing time associated with manual mixing.

\section{Methodology}

\subsection{Design Calculations}

The machine is determined by the size of the concrete to be mixed and the paddles in the drum. It is designed to contain $5 \mathrm{~kg}$ of cement, $8 \mathrm{~kg}$ of sand and $10 \mathrm{~kg}$ of gravel and at least $15 \mathrm{~kg}$ of water. Average size of sand in diameter ranges from $0.2 \mathrm{~mm}$ to $0.5 \mathrm{~mm}$.

The mass density of concrete mixture is found to be 2400 $\mathrm{kg} / \mathrm{m}^{3}$.

Total mass drum can carry $=(5+8+10+15) \mathrm{kg}=38 \mathrm{~kg}$

Hence, the machine concrete capacity $=165 \mathrm{~kg}$

\subsection{Design of Mixing Drum}

Eugene and Theodore (1996), Abdulkadir (2012) and Daniyan et al. (2016), proposed that the mass of the drum " $\mathrm{m}$ " of the concrete mixer is given by Equation 1 .

$$
m=\rho v
$$

Where $\rho$ is the density of the medium $\mathrm{kg} / \mathrm{m}^{3}$ and $v$ the volume in $\left(\mathrm{m}^{3}\right)$

$$
\begin{gathered}
v=\pi r^{2} h \\
w=\rho \pi r^{2} h g
\end{gathered}
$$

$\mathrm{w}$ is the weight of the mixer $\operatorname{drum}(\mathrm{N})$

Hence, from Equations (1) and (2)

$$
\rho \pi r^{2} h=2400 \times 3.142 \times 0.35^{2} \times 0.53=489.586 \mathrm{~kg}
$$

Every parts of the machine are subjected to torsional stress or twisting moment.

For circular sections, the maximum shear stress at the outer surface is given by Equation 4.

$$
\frac{\tau}{r}=\frac{\tau}{J}=\frac{C \theta}{l}
$$

Where; $\tau$ is the torsional shear stress at the outer surface of the shaft or maximum shear stress $\left(\frac{N}{m^{2}}\right)$

$\mathrm{r}$ is the radius of the shaft $(\mathrm{m}), \mathrm{T}$ is the torque or twisting moment $(\mathrm{Nm}), \mathrm{J}$ is the second moment of the section out the polar axis $\left(\mathrm{m} / \mathrm{s}^{4}\right), C$ is the modulus of rigidity of the shaft material in $\left.\mathrm{N} / \mathrm{m}^{2}\right), 1$ is the length of the shaft in $(\mathrm{m}), \theta$ is the angle of twist on lenght 1 in radian.

From equation 4, the twisting moment is expressed as Equation 5.

$$
T=\tau \times \frac{j}{r}
$$

The polar moment of inertia is given by Equation 6 .

$$
\begin{gathered}
j=\frac{\pi}{32} \times d^{4} \\
T=\frac{\pi}{16} \times \tau \times d^{3}
\end{gathered}
$$

\subsection{Power Transmission}

Power transmitted by shaft in watt is given by Equation 8 .

$$
\begin{gathered}
P=\mathrm{T} \omega \\
\omega=\frac{2 \pi N}{60} \\
\mathrm{P}=\frac{2 \pi N}{60} \times T
\end{gathered}
$$

Where:

$\mathrm{P}$ is the power rating of the electric motor (watt), $\mathrm{T}$ is the torque transmitted in $(\mathrm{Nm}), \omega$ is the angular speed in $(\mathrm{rad} / \mathrm{s})$ and $\mathrm{N}$ is the number of revolution per minute. Hence, the torque transmitted is expressed by Equation 11.

$$
T=m g r
$$

Where;

$\mathrm{m}$ is the mass of the drum $(489.586 \mathrm{~kg}), \mathrm{g}$ is the acceleration due to gravity, $\left(9.81 \mathrm{~m} / \mathrm{s}^{2}\right)$ and $\mathrm{r}$ is the radial distance of the shaft $(0.25 \mathrm{~m})$.

$$
\begin{gathered}
T=489.56 \times 9.81 \times 0.25 \\
T=1200.71 \mathrm{Nm}
\end{gathered}
$$

And the no of revolutions per minute $\mathrm{N}=350 \mathrm{rpm}$

From equation (10)

Where; 


$$
\begin{gathered}
P=\frac{2 \times 3.142 \times 350}{60} \times 1200.71 \\
P=44 \mathrm{~kW}
\end{gathered}
$$

\subsection{Power Requirements}

According to Abdulkadir, (2012), the force F required by the drum of mass " $\mathrm{m}$ " having a tangential acceleration " $a$ " is given by Equation 12 .

$$
F=m a
$$

Recall the equation of motion

$$
\begin{aligned}
& V=u+a t \\
& F=m \frac{2 \pi r N}{60 t}
\end{aligned}
$$

Equation 14 gives the force required for each load per second on the mixing drum.

$\mathrm{m}=489.586 \mathrm{~kg}, \mathrm{r}=0.35 \mathrm{~m}, \mathrm{~N}=350 \mathrm{rpm}$ and at $\mathrm{t}=1$ second

$$
\begin{gathered}
F=489.586 \times \frac{2 \times 3.142 \times 0.35 \times 350}{60} \\
F=6.28 \mathrm{kN}
\end{gathered}
$$

The torque $\mathrm{T}$ due to applied load is given as

$$
\begin{gathered}
T=F r \\
T=\frac{2 \pi r^{2} N m}{60}
\end{gathered}
$$

The power " $P_{T}$ " required to drive this torque is expressed by Equation 17.

$$
\begin{gathered}
P_{T}=T \omega \\
\omega=\frac{2 \pi N}{60} \\
P_{T}=\frac{2 \pi N T}{60} \\
P_{T}=m\left(\frac{2 \pi r N}{60}\right)^{2} \\
P_{T}=80,588.12 \mathrm{Watts}=80.588 \mathrm{~kW}
\end{gathered}
$$

\subsection{Shaft Design}

This is the determination of the correct shaft diameter that will ensure rigidity and strength when the shaft transmits power under different loading conditions (Hall et al., 1980; Khurmi and Gupta, 2005). The machine was designed such that the shaft receives power from the electric motor via a Vbelt. For rotating shaft, the torsional moment " $M_{t}$ " acting on the shaft is given by Equation 19.

$$
M_{t}=\frac{P \times 1000 \times 60}{2 \pi N}
$$

$$
\begin{gathered}
M_{t}=\frac{44 \times 1000 \times 60}{2 \times 3.142 \times 350} \\
M_{t}=1200.33 \mathrm{Nm}
\end{gathered}
$$

The maximum bending moment " $\mathrm{M}$ " of the shaft under the applied load is given by Equation 20 .

$$
M=\frac{w l}{4}
$$

Where;

$\mathrm{w}$ is the central point load $(419.6 \mathrm{~N})$ and $l$ is the length of the shaft $(2 \mathrm{~m})$

$\mathrm{M}=209.8 \mathrm{Nm}$

\subsection{Material Selection}

Materials are selected based on their cost, serviceability, machinability and all other mechanical and chemical properties of the material. The fact that various concrete mixing machine components would be subjected to varying degree of stress, strain, force, abrasion amongst others, hence suitable material with appropriate engineering properties were chosen. For the purpose of this work, for cost considerations and material availability, high carbon steel was mostly used for most parts while cast iron was chosen for pulley.

\subsection{Description of the Developed Concrete Mixer}

The machine is a shaft driven concrete mixer comprising of a drum, shaft, paddles, pulley, back axle and a $4.0 \mathrm{~kW}$ petrol engine. A mild steel plate is rolled into cylindrical shape with a base attached to it. The back axle is attached beneath the drum and it is connected by means of bevel gear located inside the back axle to control the rotation of the shaft in the drum. This powered rotation is produced by the petrol engine and transferred through a belt to the pulley. The mixing drum made of $3 \mathrm{~mm}$ mild steel plate is rolled into cylindrical shape to form the drum of the mixer. It has a height of $530 \mathrm{~mm}$ and a diameter of $700 \mathrm{~mm}$ and cut out from mild steel to form the base of the cylinder. An exit port $200 \mathrm{~mm}$ in length is carved out to form an opening. These parts are joined together by welding. The machine frame is constructed out of angle iron material. The drum sits on the rectangular support of $65 \mathrm{~mm} \times 65 \mathrm{~mm}$, height $500 \mathrm{~mm}$ and width of $490 \mathrm{~mm}$ held rigidly on its sides by four $50 \mathrm{~mm} \times 50 \mathrm{~mm}$ angle iron of length $700 \mathrm{~mm}$. The bearing and shaft are also held in place by two angle iron lying horizontally on the drum edges with a length of $700 \mathrm{~mm}$. The petrol engine sits on a lower support of two $50 \mathrm{mmx} 50 \mathrm{~mm}$ thick angle iron of $70 \mathrm{~mm}$ length. All these are joined together by welding. The power unit is an internal combustion engine with its pulley which rotates at a maximum speed of $3000 \mathrm{rpm}$. It is attached to the driven pulley which drives the shaft connected to the back axle mechanically to transmit motion through the gears to the shaft in the drum. The pillow bearing was used for firm support and also to prevent wobbling which will warrant changing the belt from time to time. A standard V-Belt IS-2494-1974 with adequate tension was selected for use because of great amount 
of power to be transmitted and also due to the position and distance of driving and driver gear to each other. Shafts diameter $20 \mathrm{~mm}$ and $30 \mathrm{~mm}$ were used for transmitting torque from the pulley to the back axle and from the back axle to the mixing blades respectively. The developed concrete mixer is shown in Figure 1.

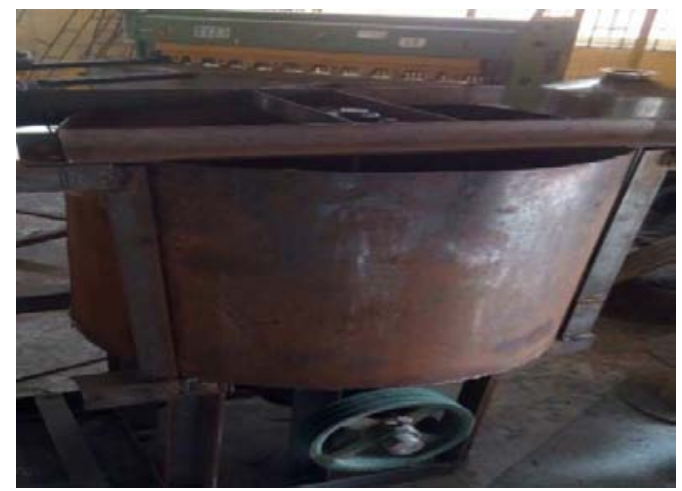

Figure 1. The Developed Concrete Mixer.

\section{Results and Discussion}

Three different sizes of cement, sand, aggregate and water were used to carry out the performance evaluation given that the petrol engine provides a constant speed of $3000 \mathrm{rpm}$. The sand used as fine aggregate was collected from the ABUAD stream, Ado Ekiti, Nigeria. It was a clean, sharp sand that is free from clay and organic matters. The coarse aggregate used was crushed stones with $15 \mathrm{~mm}$ size.

The following data were gotten from the evaluation of the concrete mixer for various sizes of concrete presented in Table 1.

Table 1. Weight of concrete and Average Time taken by Concrete Mixer.

\begin{tabular}{llll}
\hline S/N & Capacity (I) & Weight $(\mathbf{k g})$ & Average Time $(\mathbf{s e c})$ \\
\hline 1. & 0.50 & 6.80 & 20.00 \\
2. & 0.75 & 10.20 & 24.00 \\
3. & 1.50 & 19.50 & 30.00 \\
\hline
\end{tabular}

From Figure 2, it was observed that the time it takes to mix the concrete is directly proportional to the weight of the concrete mixture within the drum of the mixer. As the weight of the concrete increases the time it takes to mix the different concrete volume also increases and vice versa

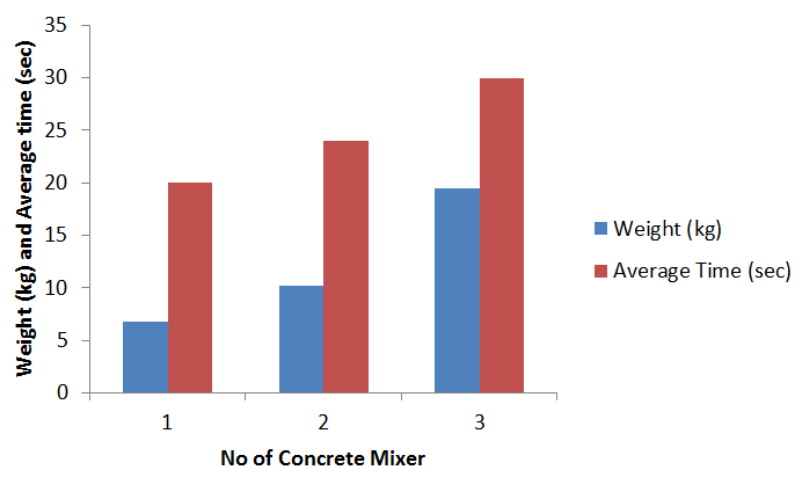

Figure 2. Weight of Concrete and Average time of Mixing.
Table 2 presents the average concrete mixing time using manual means.

Table 2. Weight of concrete and Average Time taken by Hand Mixing.

\begin{tabular}{llll}
\hline S/N & Capacity (I) & Weight $(\mathbf{k g})$ & Average Time $(\mathbf{s e c})$ \\
\hline 1. & 0.50 & 6.80 & 25.00 \\
2. & 0.75 & 10.20 & 28.00 \\
3. & 1.50 & 19.50 & 35.00 \\
\hline
\end{tabular}

From Figure 3, the processing time for the production of concrete increases when the mixing operation was performed manually as opposed to when it was performed with the developed concrete mixer. This is due to the fact the developed concrete mixer has a higher loading and unloading capacity when compared to the manual method.

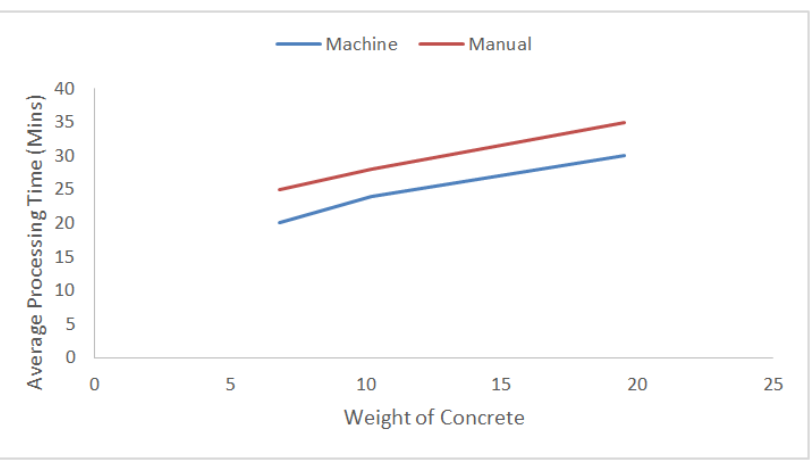

Figure 3. Comparison of Mixing time for Manual and Machine Operations.

\section{Conclusions and Recommendations}

\subsection{Conclusion}

A concrete mixer with four mixers blades or paddles for mixing concrete was developed. The peculiarities of the concrete mixer is that it is cost effective, serviceable with high loading and unloading capacity. Results obtained indicated that the developed concrete mixer is highly efficient in operation with shorter processing time and higher processing capacity as opposed to the manual method.

\subsection{Recommendations}

There should be the use of diesel engine which will allow for evaluation of the system performance at different speeds and more power. The developed system should be subjected to test throughout the year for more performance evaluation.

\section{References}

[1] Abdulkadir, B. H. (2012). Design and Fabrication of a Cassava Peeling Machine. Journal of Engineering (IOSRJEN). 2 (6): 1-8.

[2] Aguwa J. I. (2006). Effect of Critical Variable-Time on Concrete Production. Journal of Science, Technology and Mathematics Education. 8 (2) 23-39. 
[3] Aguwa, J. I. (2010). Effect of Hand Mixing on the Compressive Strength of Concrete. Leonardo Electronic Journal of Practices and Technologies. pp. 59-68.

[4] Apollo (2014). Apollo Concrete Solution: Historical Development in Concrete Batching Plants and Their Applications to Local and International Construction Sites.

[5] Berntsson, L., Chandra, S. and Kutti, T. (1990), "Principles and Factors Influencing High-Strength Concrete Production," Concrete International, December, pp. 59-62.

[6] Daniyan, I. A., Adeodu, A. O., Azeez, T. M., Dada, O. M. and Olafare, A. O. (2016). Optimization of Peeling time and Operational Speed for Cassava Peeling Using Central Composite Design and Response Surface Methodology. Int'l Journal of Engineering Sciences and Research Technology. 5(9): 630639 .

[7] Eugene, A. A. and Theodore B. (1996). Marks Standard Handbook of Mechanical Engineers, Mc Graw-Hill, New York, U.S.A.

[8] FIP/CEB. (1990), "High Strength Concrete: State of the Art Report." Bulletind' Information No. 197, London, UK, pp. 61.
[9] Hall, A. S., Holowenko, A. R. and Laughlin, H. G. (1980). Machine Design. Purdue University Press: 113-130.

[10] Hunker, H. L. (2000). Columbus, Ohio: A Personal Geography. Ohio State University Press. pp. 196.

[11] Khurmi and Gupta (2005). A text book of machine design. $\left(14^{\text {th }}\right.$ ed.). New Delhi, Eurasia Publishing House (PVT) Ltd.

[12] Liu, N. (2015). The current situation and development of concrete mixing machine industry in China. pp. 1.

[13] Peterman, M. B. and Carrasquillo, R. L. (1986). "Production of High Strength Concrete," Noyes Publications, Park Ridge, New Jersey, USA. pp. 200-278.

[14] Rashid, M. A. (2002), "Flexural Behavior of High Strength Concrete Beams", Ph. D. thesis, Dept. of Civil Engineering, National university of Singapore, Singapore.

[15] Rashid, M. A. and Mansur, M. A. (2009) Considerations in producing high strength concrete. Journal of Civil Engineering (IEB) 37 (1) (2009) $53-63$.

[16] Zhengzhouchangli (2016). The Development History of Concrete Mixer. Zhengzhouchangli Machinery Manufacturing Co. Ltd. pp. 1-5. 